Western University

Scholarship@Western

$12-1-2020$

Five-month-old male with chronic diarrhea.

Hailey C Barootes

Erin R Peebles

Dhandapani Ashok

Suzanne Ratko

Andrea C Yu

Follow this and additional works at: https://ir.lib.uwo.ca/paedpub

Part of the Pediatrics Commons 


\section{Five-month-old male with chronic diarrhea}

\section{Hailey C. Barootes MD ${ }^{1, \oplus}$, Erin R. Peebles MD FRCPC ${ }^{1}$, Dhandapani Ashok MD MBBS FRCPH ${ }^{1}$, Suzanne Ratko HBSc RD ${ }^{2}$, Andrea C. Yu MD FRCPC FCCMG ${ }^{1}$}

${ }^{1}$ Department of Paediatrics, Western University, London, Ontario; ${ }^{2}$ London Health Sciences Centre, London, Ontario

Correspondence: Andrea C. Yu, Department of Paediatrics, Western University, 1151 Richmond Street, London, Ontario N6A 3K7. Telephone 519-685-8140, fax 519-685-8214, e-mail Andrea.Yu@lhsc.on.ca

\section{CASE DESCRIPTION}

A 5-month-old term male presented with a 4-month history of failure to thrive, diarrhea, and dehydration. He was passing 10 watery, nonbloody stools per day. He was born to consanguineous parents of Old Order Amish background after an unremarkable pregnancy and delivery. His birth weight was $3.7 \mathrm{~kg}$ (50th percentile) and his newborn screen was negative. Family history was noncontributory. The patient was exclusively breastfed; his mother was on a dairy-free diet.

His weight at presentation was $5.605 \mathrm{~kg}$ (<3rd percentile) and his length was $63 \mathrm{~cm}$ (15th percentile).

Examination revealed a soft, mildly distended abdomen with active bowel sounds and no hepatosplenomegaly. He had axial and appendicular hypotonia with bilateral gluteal muscle wasting.

Initial laboratory investigations are outlined in Table 1. Stool samples were negative for bacteria, ova, parasites. The patient's diarrhea was believed to be osmotic as it ceased when feeds were held for 24 hours. He was trialled on extensively hydrolyzed formula, then an amino-acid based formula (Neocate) for suspected cow's milk protein allergy, with ongoing nonbloody diarrhea. An immunodeficiency workup was noncontributory. The patient then developed severe dehydration, hypernatremia, and hyperchloremic metabolic acidosis. Parenteral nutrition and fluid replacement was commenced while further investigations were performed, revealing the diagnosis.
Table 1. Investigations summary

\begin{tabular}{|c|c|c|c|}
\hline \multirow[t]{2}{*}{ Investigation } & \multicolumn{2}{|c|}{ Admission Admission } & \multirow{2}{*}{$\begin{array}{l}\text { Normal } \\
\text { range }\end{array}$} \\
\hline & Day 1 & Day 23 & \\
\hline $\mathrm{pH}$ & 7.39 & 7.30 & $7.35-7.45$ \\
\hline pCO2 (mmHg) & 31 & 33 & $35-45$ \\
\hline HCO3- (mmol/L) & 19.8 & 17.2 & $25-29$ \\
\hline Base Excess (mmol/L) & -5.1 & -9.1 & $-2.0-3.0$ \\
\hline $\operatorname{LKC}\left(\times 10^{9} / \mathrm{L}\right)$ & 8.7 & & $5-15$ \\
\hline $\mathrm{Hgb}(\mathrm{g} / \mathrm{L})$ & 122 & & $100-140$ \\
\hline $\operatorname{Plt}\left(\times 10^{9} / \mathrm{L}\right)$ & 335 & & $150-400$ \\
\hline Neutrophils $\left(\times 10^{9} / \mathrm{L}\right)$ & 1.9 & & $1.5-8.5$ \\
\hline Lymphocytes $\left(\times 10^{9} / \mathrm{L}\right)$ & 5.4 & & $4.0-10.5$ \\
\hline Sodium (mmol/L) & 141 & 151 & $135-145$ \\
\hline Potassium $(\mathrm{mmol} / \mathrm{L})$ & 4.2 & 4.0 & $3.5-5.0$ \\
\hline Chloride (mmol/L) & 107 & 119 & $98-107$ \\
\hline Bicarbonate (mmol/L) & 15 & 15 & $22-29$ \\
\hline Calcium (mmol/L) & 2.62 & & $2.25-2.75$ \\
\hline Magnesium (mmol/L) & 0.92 & & $0.65-1.05$ \\
\hline Phosphate (mmol/L) & 1.76 & & $1.30-2.60$ \\
\hline $\operatorname{Albumin}(\mathrm{g} / \mathrm{L})$ & 43 & & $38-54$ \\
\hline Urea $(\mathrm{mmol} / \mathrm{L})$ & 1.5 & 9.4 & $\leq 7.0$ \\
\hline Creatinine $(\mu \mathrm{mol} / \mathrm{L})$ & 11 & 14 & $\leq 53$ \\
\hline Glucose $(\mathrm{mmol} / \mathrm{L})$ & 4.9 & & $2.6-11.0$ \\
\hline Lipase (U/L) & 14 & & $13-60$ \\
\hline $\operatorname{ALT}(\mathrm{U} / \mathrm{L})$ & 18 & & $\leq 41$ \\
\hline $\operatorname{AST}(\mathrm{U} / \mathrm{L})$ & 31 & & $\leq 40$ \\
\hline $\operatorname{ALP}(\mathrm{U} / \mathrm{L})$ & 178 & & $122-469$ \\
\hline GGT (U/L) & 8 & & $\leq 204$ \\
\hline Bilirubin Total $(\mu \mathrm{mol} / \mathrm{L})$ & $<2.5$ & & $3.4-17.1$ \\
\hline Amylase (U/L) & 33 & & $28-100$ \\
\hline TSH (mIU/L) & 7.15 & & $0.73-8.35$ \\
\hline $\mathrm{CRP}(\mathrm{mg} / \mathrm{L})$ & 2.3 & & $\leq 5.0$ \\
\hline
\end{tabular}

Abnormal values are in bold.

ALP Alkaline phosphatase; ALT Alanine aminotransferase; AST Aspartate aminotransferase; CRP C-Reactive Protein; GGT Gamma-glutamyl transferase; LKC Leukocyte count; TSH Thyroid-stimulating hormone. 


\section{CASE DIAGNOSIS: GLUCOSE GALACTOSE MALABSORPTION SYNDROME}

Stool malabsorption tests returned positive for reducing substances with normal elastase, calprotectin and fat, favouring carbohydrate malabsorption. Endoscopy and flexible sigmoidoscopy with biopsies were performed to investigate for congenital enteropathies such as microvillus inclusion disease, intestinal epithelial dysplasia, and autoimmune enteropathy. Duodenal biopsies showed normal villous architecture with an intact brush border, and electron microscopy demonstrated normal microvilli within the brush border.

A search of the Amish, Mennonite, and Hutterite Genetic Disorders Database (http://www.biochemgenetics.ca/ plainpeople/) was conducted using the search term "diarrhea," given the patient's background. Results were restricted to diseases found in the Old Order Amish population. Of the three results, glucose galactose malabsorption syndrome (GGM) was consistent with the patient's presentation. The patient was trialled on Ross Carbohydrate-Free Formula with a significant decrease in his stooling and improved weight gain, supporting the diagnosis of GGM.

GGM is a rare autosomal recessive disorder that occurs due to mutations in the sodium/glucose cotransporter gene SLC5A1, located on chromosome 22q13.1. Normally, this cotransporter initiates absorption of glucose and galactose into the enterocytes through the intestinal villi. Over 40 mutations in this gene have been identified (1), all which ultimately result in unabsorbed carbohydrates in the intestinal lumen. This then leads to development of potentially life-threatening osmotic diarrhea, hyperosmolar dehydration, and metabolic acidosis, usually in the neonatal period soon after initiation of breastfeeding or formula. The diagnosis is based on evidence of glucose and galactose malabsorption as well as resolution of symptoms on a carbohydrate-free formula. It is confirmed through genetic testing. In our case, testing for Old Order Amish specific mutations in SLC5A1 identified homozygous mutations of c.1673G $>$ A (p.Arg558His).

The differential diagnosis for chronic watery diarrhea presenting at 1-month of age is broad, and includes both acquired and congenital causes. Acquired causes typically present after 1-month of age and include infectious and allergic etiologies. Most frequently reported are cow's milk protein allergy and food protein enterocolitis. Once these diagnoses have been appropriately excluded with negative stool samples and failed trials of hydrolyzed formulas, or if the infant presents prior to 1 month of age, congenital causes should be considered. These can be further subdivided into conditions with either normal or abnormal villous architecture. Endoscopic small bowel biopsies with light and electron microscopy are valuable to study villous morphology and subclassify etiologies. Conditions with abnormal villous architecture include, but are not limited to, tufting enteropathy, microvillus inclusion disease and autoimmune enteropathy. Those with normal villous architecture include disorders of abnormal electrolyte transport (congenital sodium and chloride diarrhea), protein-losing enteropathy, enteroendocrine cell loss and conditions of carbohydrate malabsorption (lactase deficiency, sucrose-isomaltase deficiency, GGM). Stool positive for reducing substances indicates presence of glucose in the stools, and further supports the diagnosis of GGM.

Early removal of glucose and galactose and initiation of a low-carbohydrate diet with fructose supplementation is vital for infants with GGM to both survive and thrive. Our patient was commenced on Ross Carbohydrate-Free Formula with fructose supplementation. His diarrhea resolved rapidly and his weight at discharge was $5.95 \mathrm{~kg}$ ( 0.5 th percentile). Two months after discharge, he continued to tolerate feeds well with passage of one formed stool per day, and his weight increased to $7.8 \mathrm{~kg}$ (17th percentile). Literature supports that patients with GGM eventually develop tolerance to carbohydrates, but the speed and degree of improvement varies (2). Most individuals in the Amish cohort tolerate diets containing carbohydrates by 20 years of age (1). Throughout childhood, they should continue to be monitored for growth, development, and presence of gastrointestinal symptoms. Genetic counselling should also be offered to parents of an affected child for future pregnancies.

\section{CLINICAL PEARLS}

1. Paediatricians encountering neonates with chronic diarrhea should consider a broad differential diagnosis. Even if the presenting medical issue is common, in those with consanguineous parents or from socially isolated populations, consideration should be given to rarer genetic conditions such as GGM.

2. GGM should be suspected when newborns present with chronic watery diarrhea associated with failure to thrive, a distended abdomen, increased bowel sounds and metabolic acidosis with hyperosmolar dehydration. A trial of carbohydrate-free formula should be considered while awaiting confirmation by genetic testing.

3. Early recognition and initiation of a low-carbohydrate diet with fructose supplementation may be life-saving and is vital to facilitate normal growth and development of affected newborns.

Informed Consent: Informed consent for publication of this case was obtained from the family in writing.

Funding: There are no funders to report for this submission.

Potential Conflicts of Interest: All authors: No reported conflicts of interest. All authors have submitted the ICMJE Form for Disclosure of Potential Conflicts of Interest. Conflicts that the editors consider relevant to the content of the manuscript have been disclosed.

\section{References}

1. Xin B, Wang H. Multiple sequence variations in SLC5A1 gene are associated with glucose-galactose malabsorption in a large cohort of Old Order Amish. Clin Genet 2011;79(1):86-91.

2. Kniffin CL. Glucose/Galactose Malabsorption; GGM. OMIM Database 1, 2002. $<$ https://www.omim.org/entry/606824> (Accessed June 7, 2019). 